\title{
Surto de toxoplasmose aguda no Município de Ponta de Pedras, Arquipélago do Marajó, Estado do Pará, Brasil: características clínicas, laboratoriais e epidemiológicas
}

\author{
Acute toxoplasmosis outbreak in the Municipality of Ponta de Pedras, Marajó \\ archipelago, Pará State, Brazil: clinical, laboratory, and epidemiological features
}

Rafaela dos Anjos Pinheiro Bogoevich Morais', Amaury Bentes Cunha Freire', Danielle Regina Lima Barbosa', Larissa de Cássia Tork da Silva', Alcione Ferreira Pinheiro', Simone Silveira da Costa ${ }^{2}$, Francisco Lúzio de Paula Ramos', Cléa Nazaré Carneiro Bichara ${ }^{3}$, Lauro José Barata Lima ${ }^{4}$, Aristeu Vieira da Silva ${ }^{5}$, Sheila Rejane Pereira de Souza ${ }^{6}$, Leotte Pimentel Piqueira Neto ${ }^{6}$, Nelson Veiga Gonçalves³, Marinete Marins Póvoa', Ediclei Lima do Carmo'

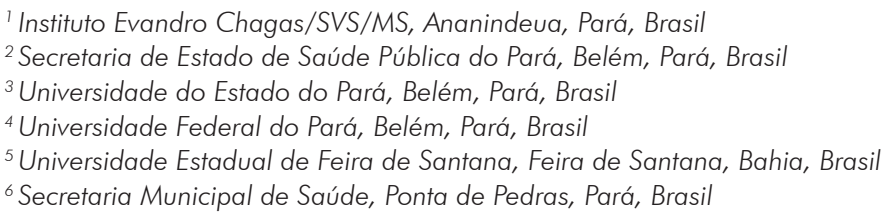

\section{RESUMO}

Introdução: Em maio de 2013, o Instituto Evandro Chagas confirmou o diagnóstico de toxoplasmose aguda em cinco indivíduos que apresentaram quadro febril linfadenopático, todos procedentes do Município de Ponta de Pedras, Estado do Pará, onde havia também outros casos similares, de acordo com a Secretaria Municipal de Saúde. Diante disso, suspeitou-se da ocorrência de um surto de toxoplasmose e, assim, uma investigação foi conduzida para identificar e caracterizar o referido evento. Objetivo: Descrever as características clínicas, laboratoriais e epidemiológicas de um surto de toxoplasmose aguda ocorrido no Município de Ponta de Pedras. Materiais e Métodos: Um total de 270 indivíduos, sintomáticos ou não, foram submetidos às análises clínica e sorológica pelo ensaio imunoenzimático para detectar $\lg G$ e $\lg M$ anti-Toxoplasma gondii. Para confirmação dos casos com perfil sugestivo de infecção aguda (lgG+/lgM+), foi determinado o índice de avidez de $\lg G$ pelo ensaio imunofluorimétrico. Por meio de questionário padronizado individual, foram obtidas informações sociodemográficas, comportamentais e sobre hábitos alimentares. Foi realizado mapeamento geográfico dos casos identificados, os quais foram analisados conjuntamente com alguns parâmetros epidemiológicos por métodos de geoestatística. Resultados: Durante a investigação, foram confirmados 73 casos com perfil clínico e laboratorial compatível com toxoplasmose aguda. Foi observada correlação espacial dos casos apenas com o consumo de suco de açaí, comercializado em três principais pontos de venda do produto, durante o surto. Conclusão: Os dados clínicos, laboratoriais e epidemiológicos demonstraram que o surto de doença aguda verificada em Ponta de Pedras foi causado pelo T. gondii. As evidências sugerem que a origem do mesmo foi alimentar, sendo o consumo de suco de açaí, provavelmente contaminado com oocistos do parasito, a fonte de contaminação.

Palavras-chave: Surtos de Doença; Toxoplasma; Toxoplasmose; Vigilância Epidemiológica.

\begin{abstract}
Introduction: In May 2013, Instituto Evandro Chagas confirmed the diagnosis of acute toxoplasmosis in five individuals with a clinical presentation of lymphadenopathy and fever. They were all from the Municipality of Ponta de Pedras, Pará State, Brazil, where other similar cases were noted by Municipal Health Secretariat. An outbreak of toxoplasmosis was suspected and an investigation was conducted. Objective: To describe the clinical, laboratory, and epidemiological characteristics of an acute toxoplasmosis outbreak in Ponta de Pedras. Materials and Methods: A total of 270 individuals, symptomatic or not, were clinically examined and had their samples analyzed using enzyme-linked immunosorbent assay to detect $\lg G$ and $\lg M$ anti-Toxoplasma gondii. To confirm cases suggestive of acute infection $(\lg G+/ \lg M+)$, the $\lg G$ avidity index was determined by immunofluorometric assay. Information on socio-demographic aspects, behavior, and eating habits was obtained using a questionnaire. Identified cases were geographically mapped, and the resultant data were analyzed together with epidemiological parameters using geo-statistic methods. Results: During the investigation, 73 cases of acute toxoplasmosis were identified. Spatial correlation of cases was observed only with the consumption of açaí juice, sold in three places during the outbreak. Conclusion: The outbreak of acute disease in Ponta de Pedras was caused by T. gondii. The evidence suggests that the origin was açaí juice, probably contaminated with oocysts of the parasite.
\end{abstract}

Keywords: Disease Outbreaks; Toxoplasma; Toxoplasmosis; Epidemiological Surveillance.

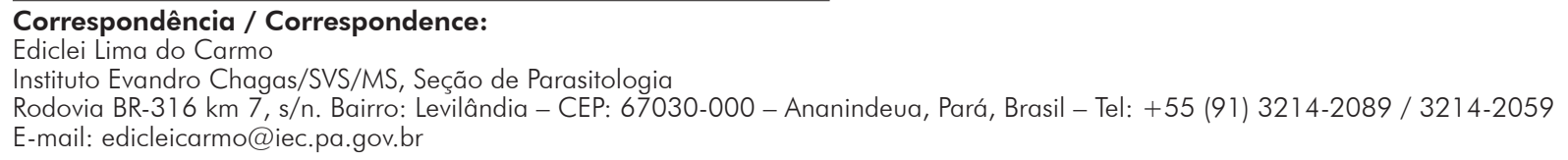




\section{INTRODUÇÃO}

A infecção causada pelo protozoário Toxoplasma gondii é uma protozoose de ampla distribuição mundial que afeta animais homeotérmicos e humanos ${ }^{1}$. Nesses, a toxoplasmose é adquirida principalmente pela via oral, por meio da ingestão de cistos presentes em carnes consumidas cruas ou mal cozidas, ou de oocistos excretados nas fezes de felídeos infectados e que podem contaminar frutas e verduras, água e solo $2,3,4$.

A toxoplasmose, apesar de ocorrer em diferentes partes do mundo, apresenta prevalência variável, sendo mais elevada em regiões tropicais, onde as condições ambientais e epidemiológicas são favoráveis ao desenvolvimento e à transmissão do parasito ${ }^{5}$. No Brasil, estudos soroepidemiológicos realizados em diferentes grupos populacionais têm demonstrado que a prevalência da infecção pode alcançar índices de até $80 \%{ }^{6}$. Além disso, devido a questões provavelmente relacionadas à diversidade genética de cepas do parasito, há a tendência de maior severidade das diferentes formas clínicas da doença no Brasili,8.

Em vários países, incluindo o Brasil, surtos de toxoplasmose aguda têm sido descritos, estando esses relacionados tanto à via hídrica quanto a possíveis fontes alimentares ${ }^{9,10,11}$. Entre essas ocorrências, destaca-se o surto de doença aguda relatado em áreas da floresta amazônica da Guiana Francesa, onde foram verificados casos graves com envolvimento ocular e multivisceral em indivíduos imunocompetentes, inclusive com registro de óbito. $\bigcirc$ referido surto foi associado à ingestão de água e/ou de carne de animais silvestres e com o envolvimento de cepas atípicas e altamente virulentas de T. gondii ${ }^{12}$.

$\mathrm{Na}$ Região Amazônica brasileira, alguns estudos demonstraram que, por suas características ecoepidemiológicas, a prevalência da infecção é alta $^{13,14,15}$ e, ainda assim, surtos de toxoplasmose aguda têm ocorrido eventualmente. Em 2004, em Monte Dourado, no Estado do Pará, foi relatado um surto envolvendo 40 indivíduos com perfil clínico e sorológico compatível com a toxoplasmose aguda, cuja transmissão foi, provavelmente, por ingestão de alimentos e/ou a inalação de poeira contaminada com oocistos de T. gondii ${ }^{16}$. Em 2011, uma investigação realizada pelo Ministério da Saúde (MS) em três Municípios do Estado de Rondônia (Ji-Paraná, Ouro Preto do Oeste e Jaru), registrou um surto com pelo menos 141 casos identificados, nos quais a provável fonte de infecção foi o consumo de suco preparado com polpa de açaí contaminada com oocistos do parasito $^{17}$.

Em maio de 2013, a partir da identificação de cinco indivíduos (pacientes índices) procedentes de Ponta de Pedras, no Arquipélago do Marajó, Estado do Pará, com perfil clínico (síndrome febril-linfadenopática) e laboratorial (lgG e lgM reagentes) compatíveis com a infecção aguda por T. gondii, atendidos no Setor de Atendimento Médico Unificado do Instituto Evandro
Chagas (IEC) e pelo relato da existência de outros indivíduos que apresentavam quadro semelhante, levantou-se a suspeita da ocorrência de surto de toxoplasmose no referido Município. Após as devidas notificações às Secretarias de Saúde do Município e do Estado e ao MS, foi realizada uma investigação prévia no local para esclarecer a ocorrência, objetivando descrever as características clínicas, laboratoriais e epidemiológicas desse evento.

\section{MATERIAIS E MÉTODOS}

\section{ÁREA INVESTIGADA}

A investigação foi realizada no Município de Ponta de Pedras, localizado no sudoeste do Arquipélago do Marajó (mesorregião do Marajó, microrregião do Arari), Estado do Pará (01²3'42"S e 4852'18"W) (Figura 1). O Município possui população estimada de 25.999 habitantes $^{18}$ e área de 3.365.148 km².

\section{INVESTIGAÇÃO PRÉVIA}

Apesar dos primeiros casos terem sido identificados no mês de maio de 2013, a primeira etapa da investigação, conduzida pela equipe do Laboratório de Toxoplasmose (LABTOXO) do IEC; foi iniciada, somente em 24 de junho de 2013, com a identificação, coleta de amostras biológicas (sangue), avaliação clínica e confirmação laboratorial dos casos.

\section{DESCRIÇÃO CLÍNICA, LABORATORIAL E EPIDEMIOLÓGICA}

Por meio do banco de dados da Secretaria Municipal de Saúde de Ponta de Pedras, criado especificamente para a investigação desse surto, foi feita a busca ativa dos indivíduos classificados inicialmente como casos suspeitos, ou seja, aqueles que apresentavam sintomas e/ou resultados sorológicos semelhantes aos apresentados pelos pacientes índices identificados no IEC. Aproveitando a estratégia de amostragem, foi feita a inclusão de outros indivíduos para posterior identificação de casos assintomáticos com perfil sorológico compatível com infecção aguda/recente.

Todos os indivíduos sintomáticos e assintomáticos foram inicialmente avaliados clinicamente por médicos infectologistas e oftalmologistas, integrantes da equipe de investigação. Em seguida, a equipe esclareceu sobre os objetivos e a importância da investigação, e aqueles que aceitaram colaborar assinaram um termo de consentimento, no qual manifestavam a concordância para coleta de sangue e de informações sobre identificação, hábitos alimentares, de exposição e comportamentais. Tais informações foram inseridas em um questionário padronizado para a investigação.

De cada indivíduo investigado, foram coletadas amostras de sangue por punção endovenosa em tubos de coleta a vácuo, para posterior obtenção de alíquotas de soro. Dos indivíduos sintomáticos, foram obtidas também amostras de sangue total coletadas com anticoagulante (EDTA), para posterior análise molecular. 

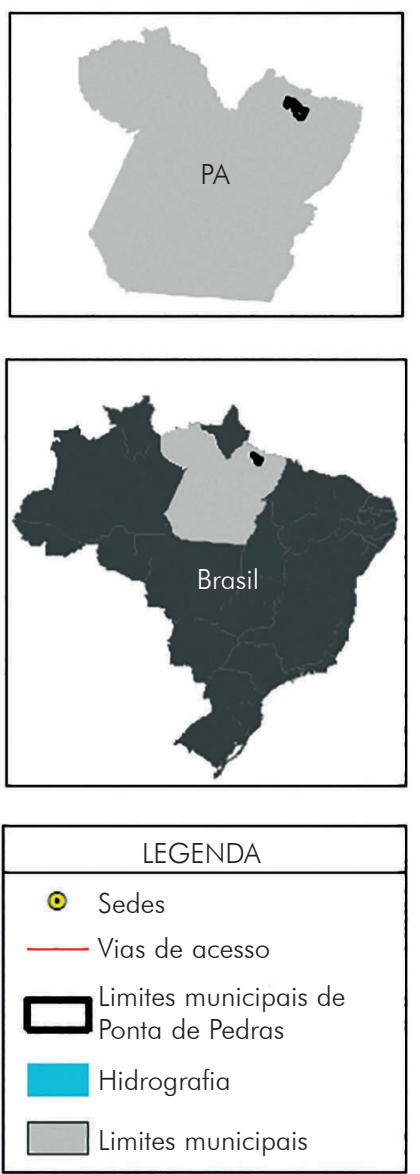

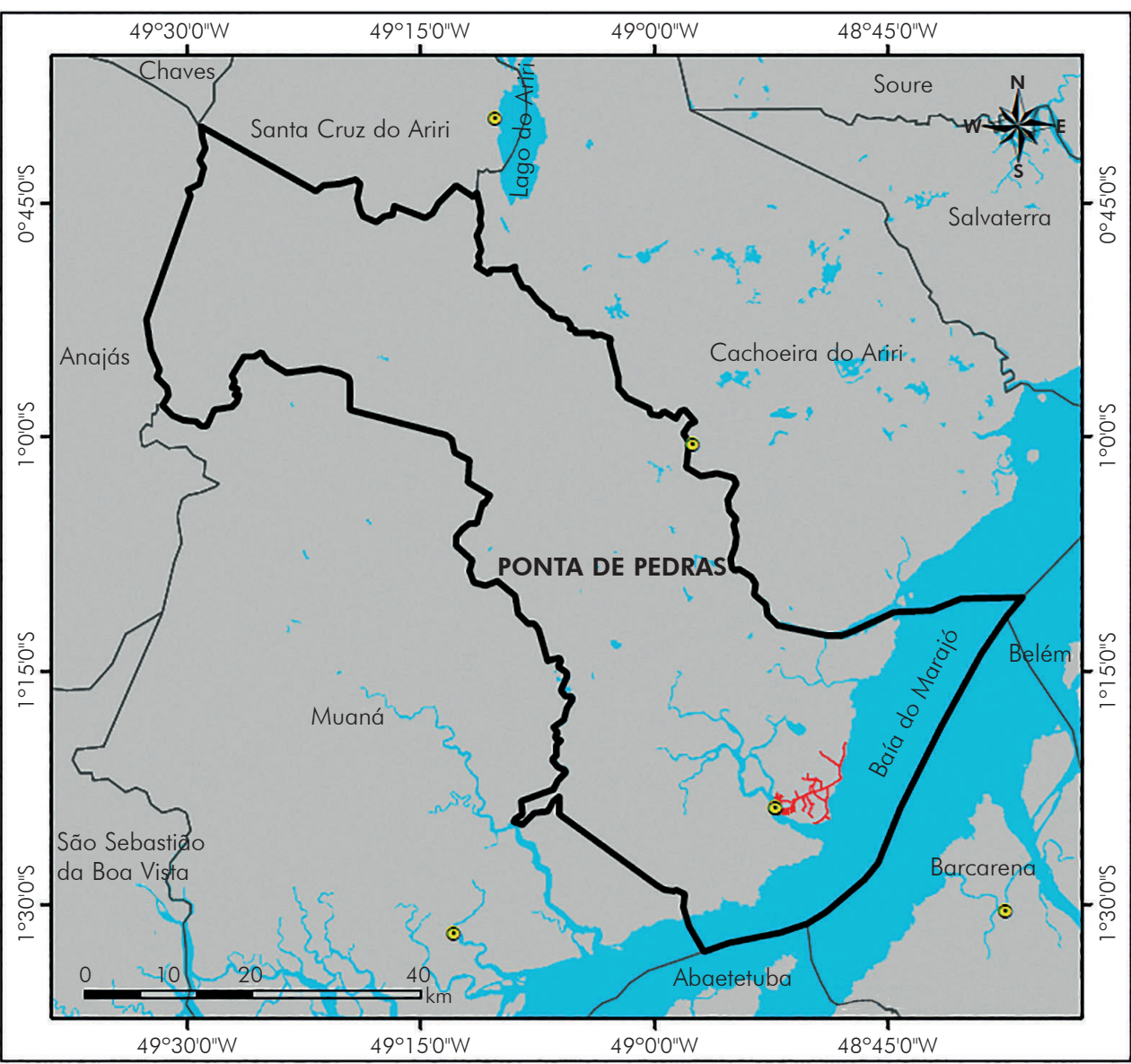

Fonte: LabGeo/IEC/SVS/MS

Figura 1 - Mapa do Município de Ponta de Pedras, Estado do Pará, Brasil

A análise sorológica realizada pelo LABTOXO/ IEC consistiu na pesquisa de anticorpos $\lg G$ e $\lg M$ anti-T. gondii pelo ensaio imunoenzimático indireto e de imunocaptura, respectivamente, utilizando kits comerciais (Symbiosys ${ }^{\circledR}$, São Paulo, Brasil). Nessa análise, os indivíduos soropositivos para lgM e para $\lg G$, independente de apresentarem ou não sintomas, foram considerados casos suspeitos; a confirmação foi feita pela determinação do índice de avidez de $\lg G$ pelo ensaio imunofluorimétrico, automatizado (VIDAS ${ }^{\circledR}$, bioMérieux, Marcy-l'Étoile, França). Foram considerados casos confirmados os indivíduos soropositivos para ambas as imunoglobulinas e com baixa avidez de $\lg G$.

Os indivíduos com ou sem sintomas, mas com soropositividade somente para $\lg G$, mais os casos suspeitos apresentando alta avidez de lgG, foram reavaliados e, com a manutenção do resultado sorológico, considerados "descartados" por apresentarem perfil de infecção pregressa. Os soronegativos para ambas as imunoglobulinas formaram o grupo controle.

Após a confirmação dos casos, a partir das amostras de sangue total de alguns deles, foi realizada a extração de DNA genômico utilizando o kit comercial QIAamp DNA Blood Mini Kit (QUIAGEN). As amostras de DNA foram posteriormente submetidas à reação em cadeia da polimerase (Nested-PCR), tendo como alvo o fragmento do gene $B 7$ do parasito e protocolo realizado conforme descrição de Okay et al ${ }^{19}$.
Algumas informações epidemiológicas que poderiam estar associadas à infecção toxoplásmica no Município foram levantadas durante essa primeira etapa de investigação. Tais informações foram organizadas em tabelas de contingência e analisadas em relação ao número de casos confirmados pelo teste de qui-quadrado com correção de Yates, o teste exato de Fischer e o cálculo da razão de chances (odds ratio), para medir a magnitude da associação (análise univariada). Para todas as análises, utilizou-se o programa BioEstat v5.020 e considerou-se o nível de significância $\alpha=0,05$.

\section{GEORREFERENCIAMENTO}

Em setembro de 2013, o Laboratório de Geoprocessamento (LabGeo) do IEC realizou o mapeamento das residências dos casos confirmados ao longo da área urbana e rural do Município. Foram também mapeados os locais de abastecimento de água dos bairros, o matadouro municipal e os principais pontos de venda de suco de açaí na época do surto. Após o levantamento das coordenadas geográficas, foi elaborado um banco de dados geográficos (BDGeo) constituído pelos principais itens de dados: código e endereço do caso, código e endereço do ponto de açaí, código e endereço do sistema de abastecimento de água, código e endereço do matadouro, latitude, longitude, ponto do GPS e altitude. Após a criação do BDGeo, foram agregados, ao mesmo, arquivos dos dados georreferenciados e o mosaico de imagens de satélites obtido do software Google Earth, tecnicamente 
tratado e geometricamente corrigido, para que fossem desenvolvidas análises de distribuição espacial dos casos. Os mapas foram gerados a partir do estimador de densidade de Kernel, que possibilita a estimação da intensidade de ocorrências dos eventos amostrados em uma determinada área em relação a sua distância de uma posição referencial. Para a análise, foram adotados, para os pontos coletados relacionados aos casos positivos do Município, um raio de 80 m e uma distância de 500 m; para análise de casos positivos com os pontos de venda de açaí, um raio de 80 m e uma distância de 300 m; enquanto que nas análises de casos positivos na área urbana e na área rural, foi utilizado um raio de $80 \mathrm{~m}$ para ambos e uma distância de 250 m e 200 m, respectivamente. Para a avaliação da possibilidade de autocorrelação espacial entre as variáveis georreferenciadas em campo, foi utilizado o cálculo do índice global de Moran $(\mathrm{IGM})^{21,22}$.

\section{RESULTADOS}

Durante o período da investigação prévia, foram avaliados 270 indivíduos e desses, 73 (27,04\%) foram definidos como casos confirmados. Foram sororreagentes para $\lg G$ e $\lg M$, porém com alto índice de avidez de $\lg G, 16$ indivíduos (5,92\%), os quais não foram considerados casos confirmados. Os demais (181, 67,04\%) foram descartados por apresentarem perfil sorológico de infecção pregressa ou de suscetibilidade (ausência de infecção).

Entre os 73 casos confirmados, a idade variou de 11 meses a 64 anos, 36 (49,3\%) pertenciam ao sexo masculino e $37(50,7 \%)$ ao feminino. Em relação à distribuição dos casos no Município, 54 (74\%) eram oriundos da zona urbana e 19 (26\%) da zona rural.
$\mathrm{Na}$ avaliação clínica dos casos confirmados, foi verificado que todos apresentavam sintomas sugestivos de toxoplasmose aguda. As principais manifestações foram: febre (94,5\%), cefaleia $(86,3 \%)$, linfadenomegalia $(84,9 \%)$ e perda de peso $(71,2 \%)$ (Figura 2). No período dessa etapa de investigação, apesar de 45,2\% dos casos relatarem manifestações oculares, como dor, fotofobia, visão turva, entre outras, na análise fundoscópica nenhum caso foi detectado de indivíduos com lesão ocular sugestiva de toxoplasmose (retinocoroidite). Da mesma forma, também não foram identificadas mulheres gestantes com perfil sorológico de infecção recente, casos graves com envolvimento multivisceral ou registro de óbitos. Alguns indivíduos relataram a persistência de sintomas por mais de um mês, principalmente o enfartamento ganglionar.

De acordo com essa primeira etapa de investigação, foi construída uma curva epidêmica prévia, baseada nas informações referentes ao início da manifestação dos sintomas pelos 73 casos identificados. Segundo relato dos indivíduos,o primeiro caso manifestou os sintomas em 22 de abril e o último em 26 de maio de 2013, com o pico do surto ocorrendo entre os dias 28 de abril e 15 de maio do referido ano (Figura 3).

Entre os casos confirmados, foi possível realizar a Nested-PCR em amostras de DNA extraídas de sangue total de 57 casos confirmados. O DNA de T. gondii foi identificado nas amostras de sangue de 52 indivíduos (91,2\%) (Figura 4).

Foram analisadas variáveis relacionadas a hábitos alimentares e comportamentais (contato com animais ou solo) dos casos confirmados, porém, nessa etapa de investigação, não foi observada nenhuma associação estatisticamente significativa (Tabela 1).

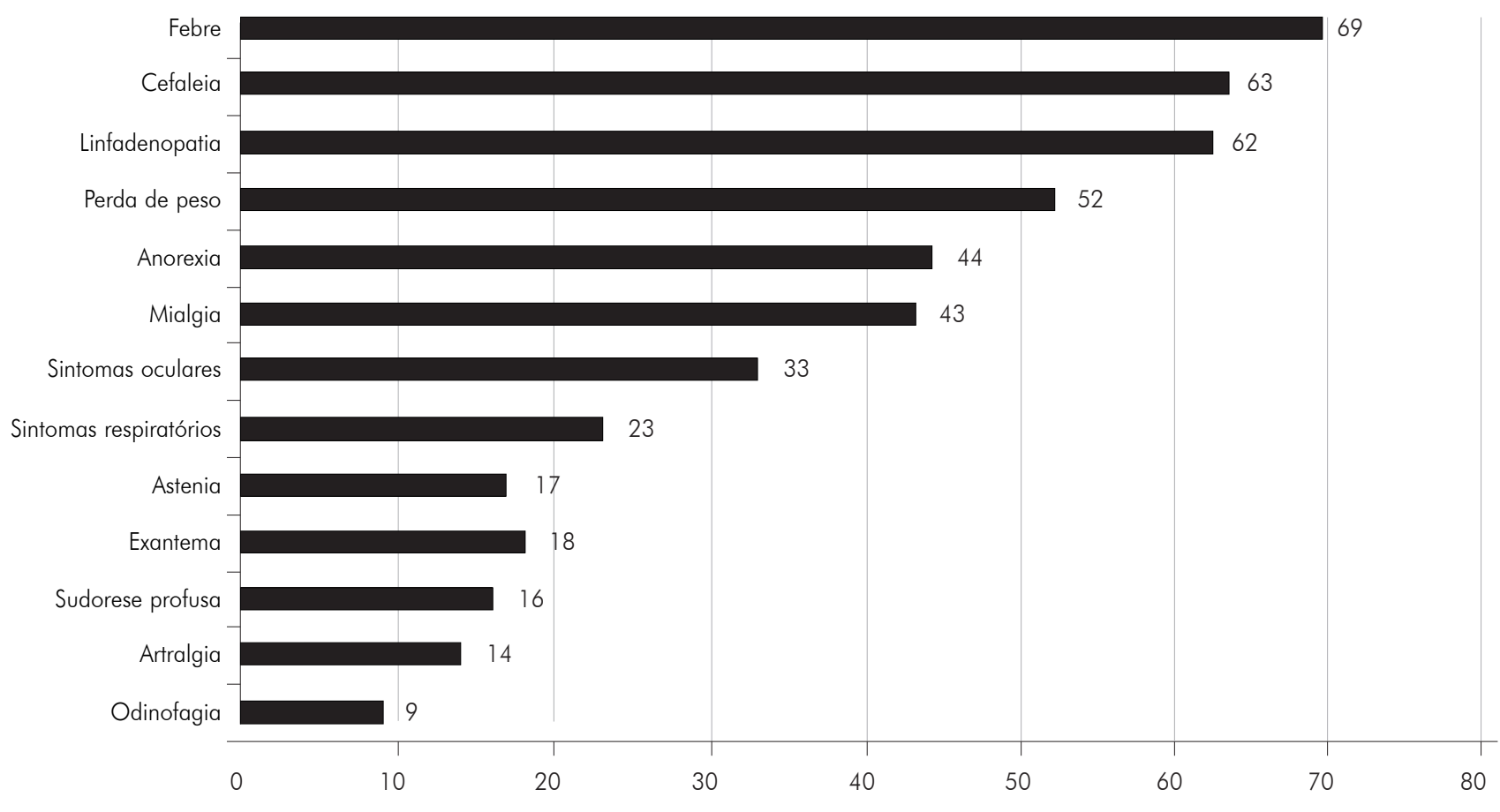

Fonte: LABTOXO/IEC/SVS/MS

Figura 2 - Distribuição dos sintomas apresentados por 73 casos sintomáticos confirmados, procedentes do Município de Ponta de Pedras, Estado do Pará, Brasil, identificados no período de 24 de junho e de 6 a 13 de julho de 2013 


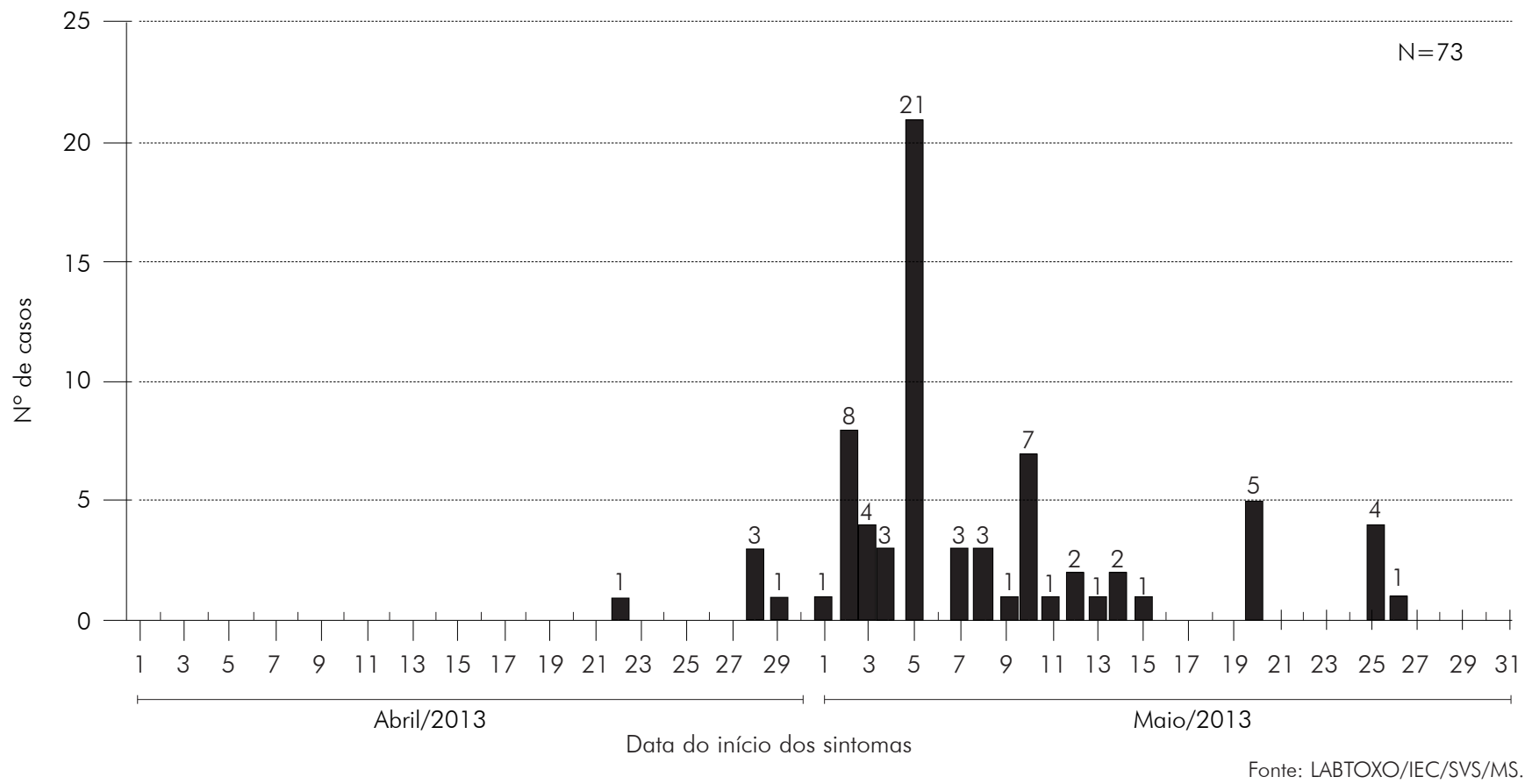

Figura 3 - Curva epidêmica de 73 casos sintomáticos confirmados no Município de Ponta de Pedras, Estado do Pará, Brasil, identificados no período de 24 de junho a 13 de julho de 2013

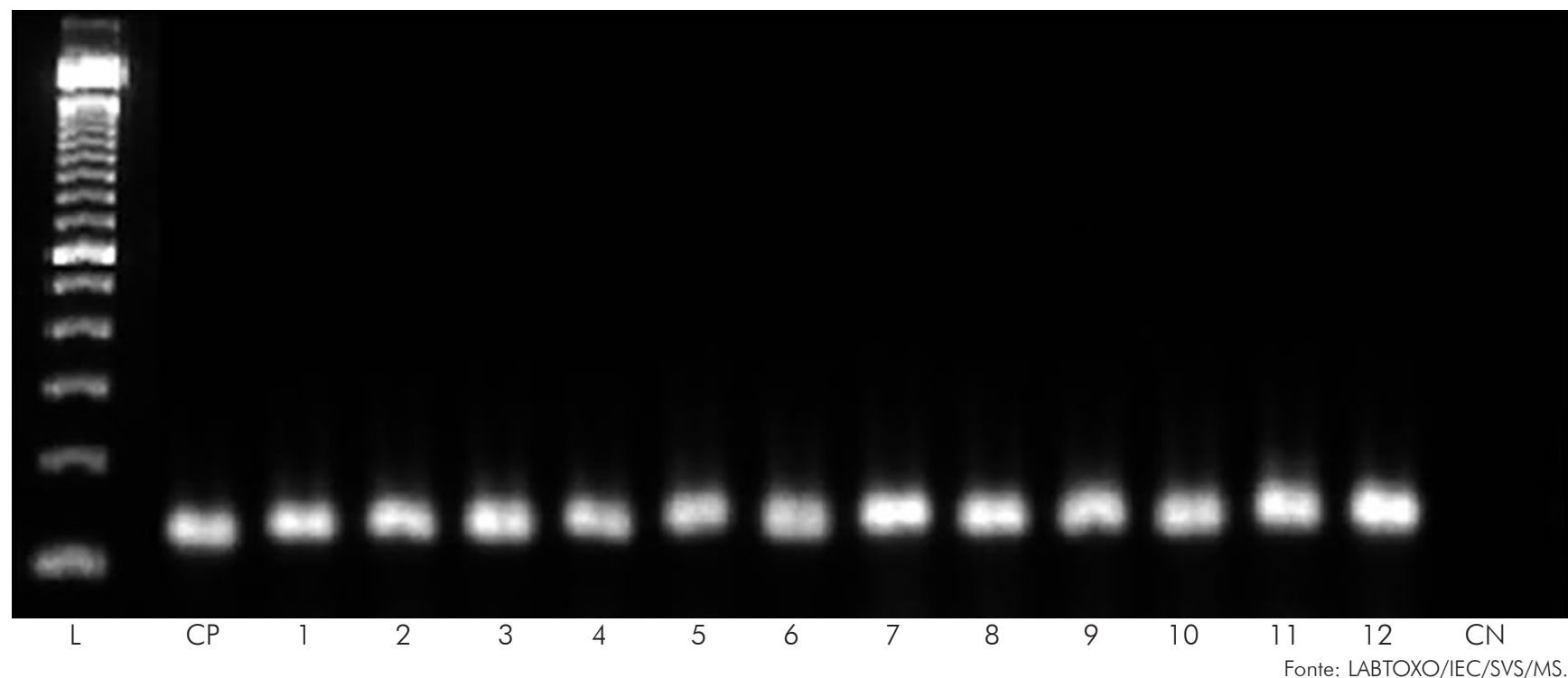

Linha 1: L - Marcador de 100 pb; Linha 2: CP - (DNA extraído de taquizoítos de T. gondii DNA- 100 ng); Linhas 3-14: Amostras de DNA dos 12 casos; Linha 15: CN - Controle negativo (DNA extraído do sangue total de um indivíduo sabidamente não infectado pelo T. gondii).

Figura 4 - Produto amplificado pela Nested-PCR (Alvo: Gene B1 de T. gondii - amplicon de 115 pb) em amostras de DNA de 12 casos confirmados no Município de Ponta de Pedras, Estado do Pará, Brasil

Em setembro de 2016, iá haviam sido registrados pela Secretaria de Saúde do Município mais 17 casos confirmados, totalizando 90 casos associados ao surto de toxoplasmose. A partir de então, foi possível fazer o mapeamento geográfico do local de residência de $95,5 \%$ (86/90) desses casos, e, com a obtenção das respectivas coordenadas geográficas, foi gerado um mapa com o estimador de densidade de Kernel, confirmando a ampla distribuição dos casos no Município, com maior concentração na área urbana (Figura 5).

Com os dados obtidos a partir do mapeamento das residências dos casos e dos prováveis pontos de interesse para o surto, foi demonstrada a evidência da relação espacial entre a concentração do número de casos de toxoplasmose e a distribuição dos principais pontos de venda de suco de açaí durante o surto, conforme relato dos pacientes. Na figura 5, é possível observar a estimativa da densidade de Kernel para os casos confirmados e sua proximidade espacial com os pontos de venda mais citados (estabelecimentos A e $\mathrm{B}$ na área urbana e estabelecimento $\mathrm{Z}$ na área rural). Na sequência, foi gerado o índice de autocorrelação espacial IGM, entre as duas variáveis (caso e ponto de comercialização citado), em cada uma das áreas isoladamente e os valores observados foram 0,820054 $(p=0,01)$ e 0,456959 ( $p=0,02)$ para área urbana e rural, respectivamente. 
Tabela 1 - Variáveis epidemiológicas avaliadas durante o período de 24 de junho a 13 de julho de 2013, durante o surto associado à toxoplasmose no Município de Ponta de Pedras, Estado do Pará, Brasil

\begin{tabular}{|c|c|c|c|c|}
\hline Variáveis epidemiológicas & $\%$ & OR & IC $95 \%$ & $p$ \\
\hline \multicolumn{5}{|l|}{ Hábitos alimentares } \\
\hline Não ferve ou filtra a água consumida & $24,6(18 / 73)$ & 1,16 & $0,48-2,83$ & 0,88 \\
\hline Consumo de vegetais crus & $98,6(72 / 73)$ & 2,44 & $0,17-69,81$ & 0,59 \\
\hline Consumo de leite in natura & $2,7(2 / 73)$ & 0,54 & $0,06-3,79$ & 0,66 \\
\hline Consumo de polpa de fruta comercial & $10,9(8 / 73)$ & 0,56 & $0,21-1,49$ & 0,36 \\
\hline Consumo de carne suína* & $58,9(43 / 73)$ & 0,60 & $0,29-1,23$ & 0,22 \\
\hline Consumo de carne de caça* & $35,6(26 / 73)$ & 0,74 & $0,37-1,49$ & 0,56 \\
\hline Consumo de frango caipira* & $50,7(37 / 73)$ & 0,82 & $0,41-1,61$ & 0,68 \\
\hline Consumo de carne bovina mal passada/crua & $12,3(9 / 73)$ & 1,57 & $0,49-4,98$ & 0,62 \\
\hline Consumo de camarão seco & $19,2(14 / 73)$ & 0,97 & $0,41-2,28$ & 0,88 \\
\hline Consumo de embutidos caseiros & $2,7(2 / 73)$ & 0,32 & $0,05-1,69$ & 0,24 \\
\hline Consumo de açaí & $100,0(73 / 73)$ & IND & IND & 0,09 \\
\hline Hábito de comer fora de casa & $78,1(57 / 73)$ & 1,27 & $0,57-2,81$ & 0,70 \\
\hline \multicolumn{5}{|l|}{ Contato com animais/solo } \\
\hline Contato com gato & $75,3(55 / 73)$ & 0,67 & $0,29-1,56$ & 0,47 \\
\hline Contato com fezes de gato & $30,7\left(20 / 65^{\dagger}\right)$ & 1,30 & $0,59-2,87$ & 0,64 \\
\hline Contato com cão & $46,5(34 / 73)$ & 1,22 & $0,61-2,43$ & 0,69 \\
\hline Contato com solo & $73,6\left(53 / 72^{\dagger}\right)$ & 0,48 & $0,20-1,16$ & 0,15 \\
\hline
\end{tabular}

* Todos os indivíduos relataram consumir a carne desses animais sempre bem cozida; ${ }^{\dagger}$ Número de casos que responderam a pergunta referente a essa variável; \%: Frequência relativa de casos expostos às referidas variáveis; OR: Odds ratio; IC: Intervalo de confiança; IND: Indeterminado.
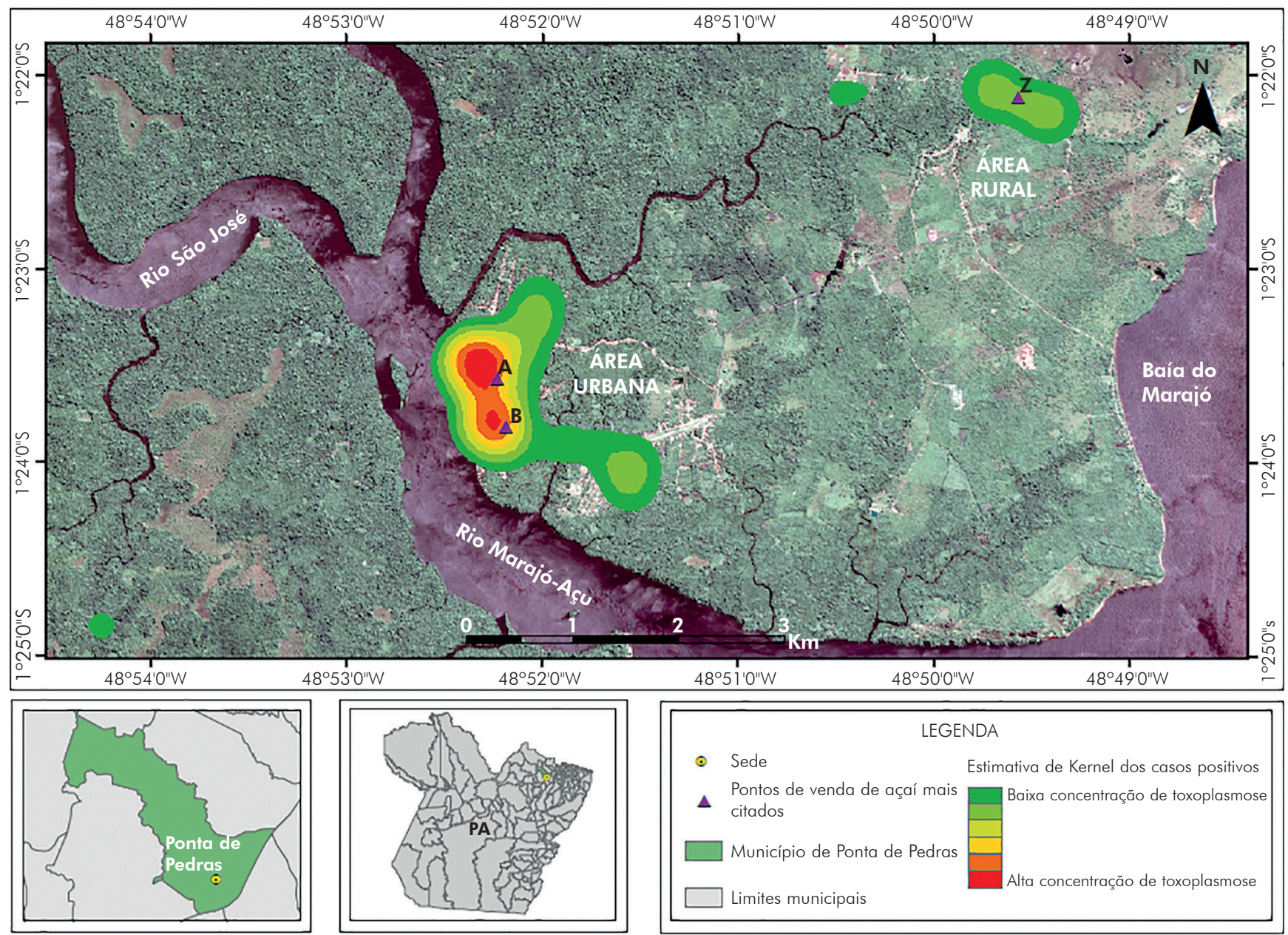

Figura 5 - Densidade de Kernel da distribuição dos 86 casos confirmados para toxoplasmose e dos pontos de venda de açaí mais citados pelos pacientes do Município de Ponte de Pedras, Estado do Pará, Brasil 


\section{DISCUSSÃO}

A partir dos critérios clínicos e laboratoriais observados, ficou demonstrado que o surto ocorrido em Ponta de Pedras estava associado à infecção aguda/recente pelo protozoário $T$. gondii. $\bigcirc$ referido surto foi caracterizado pelo número elevado de pessoas acometidas, total de 90 casos, ao contrário do que foi observado na maioria dos outros surtos registrados no Brasil 11,23. Apesar disso, ficou abaixo dos casos registrados nos surtos ocorridos em Santa Isabel do Ivaí, no Estado do Paraná, em 2001-2002 (426 casos) $)^{9}$ e em municípios do Estado de Rondônia $(141 \text { casos })^{17}$.

Assim como foi observado em outros surtos no Brasil $^{9,10,17}$, inclusive no próprio Pará ${ }^{16}$, a maioria dos pacientes era sintomática, com predomínio de quadro febril acompanhado de cefaleia e linfadenopatia, principalmente na região cervical, quadro clínico clássico em casos de toxoplasmose aguda. No entanto, outros sintomas pouco comuns na doença, como mialgia e manifestações respiratórias, também foram frequentes. Apesar dos vários sintomas manifestados, a gravidade da doença foi considerada aparentemente moderada, inclusive, não sendo registrados casos de mulheres gestantes com infecção aguda com consequente transmissão congênita, indivíduos com manifestações multiviscerais graves ou com lesões oculares, como observado nos surtos ocorridos na Guiana Francesa e em localidades da Região Amazônica brasileira 10,16,17.

Apesar da ausência de casos graves durante - surto, a diversidade e a exuberância clínica apresentadas pelos pacientes, bem como a persistência de alguns desses sintomas por período superior a um mês, sugerem que cepas com genótipos atípicos do parasito estejam associadas ao surto, visto que estudos genéticos já evidenciaram a circulação dessas cepas na região ${ }^{24}$. Na presente investigação, não foi possível realizar o isolamento de cepas do parasito em espécimes biológicos humanos, porém, as amostras que apresentaram positividade pela Nested-PCR, serão posteriormente caracterizadas para determinação dos genótipos das cepas envolvidas.

Baseado no período médio de incubação da doença e nas datas do surgimento dos primeiros sintomas, estimou-se que o surto tenha iniciado na segunda quinzena do mês de abril de 2013, porém, a maioria das pessoas apresentaram sintomatologia no início do mês seguinte. Além disso, é possível inferir que a origem do surto ocorreu por uma fonte comum, visto que os indivíduos suscetíveis foram expostos em um determinado período a essa fonte que foi esgotada, pois não houve registro de casos novos. Tal situação assemelha-se à observada em outros surtos associados à infecção pelo T. gondii 9 ,25,26.

Na análise de diferentes variáveis epidemiológicas que poderiam estar associadas à transmissão da toxoplasmose, nenhuma apresentou associação significativa, principalmente aquelas relacionadas com o consumo de água não tratada (fervida e filtrada) e outros alimentos de origem animal e vegetal, possibilidades clássicas na cadeia de transmissão e consideradas como fontes de infecção em outros surtos registrados $9,10,17,26,27$.

Apesar da maior concentração dos casos ter ocorrido na zona urbana, o surto foi caracterizado por apresentar casos dispersos em todo o Município. - cenário epidemiológico observado, a princípio, assemelhava-se ao observado no surto de Santa Isabel do Ivaíi ; dessa forma, aventou-se a possibilidade da veiculação hídrica de oocistos esporulados de T. gondii como possível fonte de origem do surto. Apesar de não ter sido possível fazer associações epidemiológicas entre os casos confirmados no momento em que a investigação prévia foi realizada, as características dos sistemas de captação e distribuição de água potável mostraram que, nas localidades rurais, a água oferecida era captada de poços profundos e sem nenhuma interligação com o sistema da área urbana. Além disso, em ambas as áreas, os sistemas aparentemente não apresentavam falhas estruturais que os tornassem vulneráveis à contaminação com formas infectantes do parasito. Posteriormente, um estudo caso-controle, realizado por equipes do MS (EpiSUS), da Secretaria de Estado de Saúde Pública do Pará (SESPA) e de técnicos do Município, corroborou essa evidência e descartou a possibilidade do surto ter se originado a partir da veiculação hídrica de oocistos do parasito (dados não publicados) ${ }^{28}$.

Durante a investigação, foram levantadas suspeitas por parte da mídia e da população sobre o possível envolvimento da carne consumida no Município como fonte de origem do surto. Apesar de ser uma variável importante na cadeia de transmissão da toxoplasmose, essa possibilidade foi inicialmente descartada, pois, apesar de ser frequentemente consumida na região, em especial a bovina, em Ponta de Pedras, de 90 a $100 \%$ dos casos referiram não fazer consumo de qualquer tipo de carne crua ou mal cozida, forma clássica de transmissão da toxoplasmose pela via do carnivorismo2. Esse fato também foi confirmado no estudo caso-controle realizado posteriormente no Município (dados não publicados) ${ }^{28}$.

No Arquipélago do Marajó e na Região Amazônica, um dos alimentos mais frequentemente consumidos pela população é o açaí na forma de suco. Esse fato, somado à ampla dispersão dos casos e aos relatos prévios do possível envolvimento do açaí como fonte de outros surtos de toxoplasmose, o consumo desse alimento foi considerado como uma das possibilidades. Como já era esperado, quase 100\% dos munícipes investigados, entre eles os casos confirmados e os indivíduos suscetíveis, relataram ter consumido esse alimento no período, ou seja, a princípio poderia ser uma possibilidade descartada. Contudo, análises por métodos de geoestatística demonstraram forte correlação entre a distribuição espacial dos casos e os estabelecimentos que concentravam a venda do produto durante o desencadeamento do surto, aqui denominados estabelecimento $A$ e $B$ na zona urbana 
e Z na zona rural do Município, fornecendo, assim, evidências que apontavam o consumo do açaí como provável fonte que originou o surto, fato corroborado posteriormente no estudo caso-controle realizado pelas outras instituições envolvidas na investigação (dados não publicados) $^{28}$.

O Município de Ponta de Pedras é um dos principais produtores de açaí do Estado do Pará; porém, é importante ressaltar que o surto ocorreu no período em que a produção local de açaí é praticamente nula (entressafra) 29,30 . Nesse período, para garantir a demanda da população, os vendedores de açaí adquirem o fruto de outras localidades onde a safra está mantida. Tal fato sugere que o fruto que chegou ao Município foi contaminado com formas infectantes do parasito (oocistos) durante as etapas de produção que envolvem colheita, transporte e distribuição dos frutos, ou mesmo durante o processamento e consumo final do suco. Dessa forma, a hipótese sugerida é que esse alimento, por ter sido amplamente consumido por indivíduos suscetíveis de áreas urbana e rural, pode ter desencadeado o surto da doença. É importante atentar para o fato de que, caso tal situação seja verdadeira, existe um alto risco de dispersão de cepas de T. gondii entre diferentes localidades da Região Amazônica, - que pode levar à ocorrência de novos surtos e a formas mais graves da doença. Sendo assim, vale destacar que as boas práticas para o manuseio na colheita, transporte e processamento da polpa do açaí devem ser sempre recomendadas aos produtores pelos órgãos de fiscalização e vigilância sanitária da região.

Uma revisão recente acerca de surtos associados ao T. gondii, descritos no Brasil e em outras localidades do mundo, demonstrou que surtos originados pela veiculação hídrica de oocistos geralmente apresentam maior número de casos, como os ocorridos em Greater Victoria, no Canadá $^{31}$ e em Santa Isabel do Ivaí, no Brasil' . Já em relação a surtos desencadeados pela via alimentar, seja pelo consumo de carne e/ou derivados contendo cistos teciduais ou por outros alimentos contaminados com oocistos esporulados, normalmente o número de casos é menor, estando limitado a grupos familiares, participantes de festas, empregados de empresas, entre outros ${ }^{10,11,25,32}$.

Nos surtos registrados em Rondônia ${ }^{17}$ e em Ponta de Pedras, onde a fonte alimentar que desencadeou o evento, no caso o consumo do açaí, que seria a maior suspeita, o padrão relacionado ao número elevado e à ampla dispersão de casos difere dos demais surtos de grande magnitude. Contudo, na situação específica de Ponta de Pedras, é importante ressaltar que não foi possível realizar experimentos que viabilizassem $o$ isolamento ou detecção do parasito em amostras daquele alimento, devido ao intervalo de tempo entre o período do surto e o início da investigação, aproximadamente dois meses, que impossibilitou a obtenção de amostras durante a ocorrência do evento. A dificuldade para se determinar a fonte de surtos causados pelo T. gondii, devido à demora da notificação e do início da investigação, é uma realidade demonstrada em outros surtos de toxoplasmose investigados no Brasil ${ }^{24,32}$.

Com o esclarecimento da etiologia do surto, o tratamento específico foi disponibilizado para todos os casos, até então, identificados. Apesar de não terem sido registradas gestantes infectadas, atualmente $\mathrm{O}$ IEC, em colaboração com a Secretaria Municipal de Saúde de Ponta de Pedras, realiza o acompanhamento sorológico das mulheres gestantes cadastradas no Programa de Assistência Pré-Natal, incluindo o monitoramento das soronegativas. Além disso, os indivíduos que foram confirmados como casos do surto têm realizado avaliações oftalmológicas periódicas, a fim de evitar o comprometimento ocular associado à retinocoroidite ocasionada pela infecção por $T$. gondii, visto que ainda há a possibilidade de evolução para possíveis lesões oculares em período de até um ano após a infecção aguda ${ }^{33}$. Somando-se a isso, estudos na área continuam sendo realizados pelo LABTOXO IEC, a fim de melhor esclarecer a epidemiologia da toxoplasmose e de tentar o isolamento e caracterização genotípica das cepas circulantes na região.

\section{CONCLUSÃO}

As características clínicas e laboratoriais observadas nesta investigação confirmaram que o protozoário $T$. gondii foi o agente responsável pelo surto de doença aguda ocorrido no primeiro semestre de 2013 em Ponta de Pedras. As características epidemiológicas e as análises baseadas em dados geoestatísticos sugerem que a origem do surto estaria associada ao consumo de suco de açaí contaminado com oocistos do parasito durante a coleta, transporte ou processamento desse produto.

\section{AGRADECIMENTOS}

À Prefeitura Municipal de Ponta de Pedras; aos servidores da Secretaria de Saúde do Município, pelo apoio administrativo, técnico e logístico durante esta investigação; e aos técnicos da Seção de Parasitologia do IEC/SVS/MS que colaboraram durante as etapas de investigação de campo e análise laboratorial.

\section{REFERÊNCIAS}

1 Dubey JP, Jones JL. Toxoplasma gondii infection in humans and animals in the United States. Int J Parasitol. 2008 Sep;38(1 1):1257-78.
2 Tenter AM. Toxoplasma gondii in animals used for human consumption. Mem Inst Oswaldo Cruz. 2009 Mar; 104(2):364-9. 
3 Jones LJ, Dubey JP. Foodborne Toxoplasmosis. Clin Infect Dis. 2012 Sep;55(6):845-51.

4 Lass A, Pietkiewicz H, Szostakowska B, Myjak P. The first detection of Toxoplasma gondii DNA in environmental fruits and vegetables samples. Eur J Clin Microbiol Infect Dis. 2012 Jun;31(6): 1101-8.

5 Robert-Gangneux F, Dardé ML. Epidemiology of and diagnostic strategies for toxoplasmosis. Clin Microbiol Rev. 2012 Apr;25(2):264-96.

6 Dubey JP, Lago EG, Gennari SM, Su C, Jones $\mathrm{JL}$. Toxoplasmosis in humans and animals in Brazil: high prevalence, high burden of disease, and epidemiology. Parasitology. 2012 Sep;139(1 1):1375-424.

7 Khan A, Jordan C, Muccioli C, Vallochi AL, Rizzo LV, Belfort Jr R, et al. Genetic divergence of Toxoplasma gondii strains associated with ocular toxoplasmosis, Brazil. Emerg Infect Dis. 2006 Jun; 12(6):942-9.

8 Carneiro AC, Andrade GM, Costa JGL, Pinheiro BV, Vasconcelos-Santos DV, Ferreira AM, et al. Genetic characterization of Toxoplasma gondii revealed highly diverse genotypes for isolates from newborns with congenital toxoplasmosis in southeastern Brazil. J Clin Microbiol. 2013 Mar;51(3):901-7.

9 De Moura L, Bahia-Oliveira LM, Wada MY, Jones JL, Tuboi SH, Carmo EH, et al. Waterborne toxoplasmosis, Brazil, from field to gene. Emerg Infect Dis. 2006 Feb;12(2):326-9.

10 Ekman CCJE, Chiossi MFV, Meireles LR, Andrade Júnior HF, Figueiredo WM, Marciano MAM, et al. Case-control study of an outbreak of acute toxoplasmosis in an industrial plant in the state of São Paulo, Brazil. Rev Inst Med Trop S Paulo. 2012 Sep-Oct;54(5):239-44.

11 Meireles LR, Ekman CC, Andrade Jr HF, Luna EJ. Human toxoplasmosis outbreaks and the agent infecting form. Findings from a systematic review. Rev Inst Med Trop S Paulo. 2015 SepOct;57(5):369-76.

12 Demar M, Ajzenberg D, Maubon D, Djossou $F$, Panchoe D, Punwasi W, et al. Fatal outbreak of human toxoplasmosis along Maroni River: epidemiological, clinical, and parasitological aspects. Clin Infect Dis. 2007 Oct;45(7):e88-85.

13 Cavalcante GT, Aguiar DM, Camamrgo LM, Labruna MB, Andrade HF, Meireles LR, et al. Seroprevalence of Toxoplasma gondii antibodies in humans from rural Western Amazon, Brazil. J Parasitol. 2006 Jun;92(3): 647-9.

14 Carmo EL. Aspectos epidemiológicos da toxoplasmose na região metropolitana de Belém, Pará, Brasil [tese]. Belém (PA): Instituto de Ciências Biológicas, Universidade Federal do Pará; 2011.
15 Vitaliano SN, Mendonça GM, Sandres FA, Camargo JS, Tarso P, Basano SA, et al. Epidemiological aspects of Toxoplasma gondii infection in riverside communities in the Southern Brazilian Amazon. Rev Soc Bras Med Trop. 2015 May-Jun;48(3):301-6.

16 Carmo EL, Póvoa MM, Monteiro NS, Marinho RR, Nascimento JM, Freitas SN, et al. Surto de toxoplasmose humana no Distrito de Monte Dourado, município de Almeirim, Pará, Brasil. Rev Pan-Amaz Saude. 2010 Mar;1(1): 61-6.

17 Dutra LH, Saad E, Alves RMS, Cabral CM, Batista FS, Lima R, et al. Investigação de surto de toxoplasmose transmitido pelo consumo de açaí em Rondônia, Brasil, 2011. Anais da 12a EXPOEPI: mostra nacional de experiências bem-sucedidas em epidemiologia, prevenção e controle de doenças; 2012 nov 16-19; Brasília, Brasil. Brasília (DF): Ministério da Saúde; 2012. p. 108-9.

18 Instituto Brasileiro de Geografia e Estatística. Censo demográfico, 2010. Rio de Janeiro: IBGE; 2010.

19 Okay TS, Yamamoto L, Oliveira LC, Manuli ER, Andrade Júnior HF, Del Negro GMB. Significant performance variation among PCR systems in diagnosing congenital toxoplasmosis in São Paulo, Brazil: analysis of 467 amniotic fluid samples. Clinics. 2009 Mar;64(3):171-6.

20 Ayres M, Ayres JRM, Ayres DL, Santos AS. BioEstat 5.0: aplicações estatísticas nas áreas das ciências bio-médicas. Belém: Instituto de Desenvolvimento Sustentável Mamirauá; 2007. 364 p.

21 Câmara G, Carvalho MS. Análise espacial de eventos. In: Druck S, Carvalho MS, Monteiro AMV, editores. Análise espacial de dados geográficos. Planaltina: EMBRAPA; 2004. p. 55-75.

22 Câmara G, Carvalho MS, Cruz OG, Correa V. Análise espacial de áreas. In: Druck $S$, Carvalho MS, Monteiro AMV, editores. Análise espacial de dados geográficos. Planaltina: EMBRAPA; 2004. p. 157-206.

23 Dias RAF, Freire RL. Surtos de toxoplasmose em seres humanos e animais. Semina. 2005 abrjun;26(2):239-48.

24 Vitaliano SN, Soares HS, Minervino $A H H$, Santos ALQ, Werther K, Marvulo MFV, et al. Genetic characterization of Toxoplasma gondii from Brazilian wildlife revealed abundant new genotypes. Int J Parasitol. 2014 Dec;3(3): 276-83.

25 Ministério da Saúde (BR). Secretaria de Vigilância em Saúde. Surto de toxoplasmose adquirida, Anápolis-GO, fevereiro de 2006. Bol Eletr Epidemiol. 2007 nov;7(8): 1-6. 
26 Ministério da Saúde (BR). Secretaria de Vigilância em Saúde. Investigação de casos de toxoplasmose aguda em Paraty e Angra dos Reis - Rio de Janeiro, Agosto de 2010. Bol Epidemiol. 2012;43(2):12-6.

27 Eduardo MBP, Katsuya EM, Ramos SRTS, Pavanello El, Paiva OR, Brito SN, et al. Investigação do surto de toxoplasmose associado ao consumo de prato à base de carne crua ("steak tartar"), nos municípios de São Paulo e Guarujá - Novembro de 2006. Bol Epidemiol Paulista. 2007 mai;4(41):1-7.

28 Ministério da Saúde (BR). Secretaria de Vigilância em Saúde. Investigação de surto de toxoplasmose no município de Ponta de Pedras/Pará, 2013 - relatório final. 2013. 22 p. Localizado em: Arquivo da Secretaria Municipal de Saúde de Ponta de Pedras, Ponta de Pedras, PA.

29 Nogueira AKM, Santana AC. Análise da sazonalidade de preços de varejo do açaí, cupuaçu e bacaba no Estado do Pará. Rev Estud Soc. $2009 ; 11(21): 7-22$.
30 Vicente ASC. Açaizais cultivados em terra firme no Estado do Pará. Belém: Amazônia Irrigação; 2010.

31 Bowie WR, King AS, Werker DH, Isaac-Renton JL, Bell A, Eng SB, et al. Outbreak of toxoplasmosis associated with municipal drinking water. Lancet. 1997 Jul;350(9072):173-7.

32 Ministério da Saúde (BR). Secretaria de Vigilância em Saúde. Surto intrafamiliar de toxoplasmose, Santa Vitória do Palmar, RS, Julho de 2005. Bol Eletr Epidemiol. 2006 out;(6)3:1-7.

33 Silveira C, Muccioli C, Holland GN, Jones JL, Yu F, Paulo A, et al. Ocular Involvement Following an Epidemic of Toxoplasma gondii Infection in Santa Isabel do Ivaí, Brazil. Am J Ophthalmol. 2015 Jun; 159(6): 1013-21.

Recebido em / Received: 23/6/2016 Aceito em / Accepted: 30/9/2016 